\title{
HEAT TREATMENT ON THE STRUCTURAL AND MICRO- STRUCTURAL PROPERTIES IN Ni-Zn FERRITES SYNTHESIZED BY COMBUSTION REACTION
}

\author{
da Cunha, F.A.P; Sales, L.L.M.; Fregolente, D.; Silva, J. M.; Wanderley, A. F.
}

Centro de Formação de Professores, Universidade Federal de Campina Grande, Cajazeiras/PB, Brazil

*b.jesana_moura@hotmail.com

Ceramic materials formed by complex metal oxides are assuming a very important role on the scientifically and technological development. The synthesis by reaction of combustion is of particular interest once it is a very quick and cheap method to obtain products with both levels of purity and excellent reproducibility. The method is based on a highly exothermic reaction that provides the necessary energy for the chemical transformation and the obtaining of reasonable ceramic products. This result must be confirmed by JCPDF 52-0279 chart, obtained products are monophasic. The present work aims to synthesize and characterize the $\mathrm{Zn}_{0,5} \mathrm{Ni}_{0,5} \mathrm{Fe}_{2} \mathrm{O}_{4}$ in order to relate the micro-structural properties. The analysis of the thermal treatment effect generates a duplication of the crystallinity values related to material. The thermal treatment leading to a rising of the crystallinity of sample confirmed by the crystallite size of $422.4 \mathrm{~nm}$. 